\title{
O diagnóstico organizacional em agroindústrias familiares: um estudo em uma agroindústria familiar rural
}

Este estudo objetivou diagnosticar e analisar a dinâmica organizacional que se estabelece na interface das áreas funcionais de planejamento organizacional, marketing, produção e operações, gestão de pessoas e de finanças sob o impacto das variáveis do meio social e das dimensões indivíduo-grupo-sistema organizacional, além de descrever as interfaces, potencialidades e fragilidades que se estabelecem. Nesse contexto, procurou-se apresentar, em um âmbito mais completo e aprofundado, o diagnóstico organizacional da Agroindústria Sete Sabores, uma agroindústria familiar rural localizada no interior da cidade de ljuí (RS), que atua no ramo de produção de produtos na linha de panificados e confeitaria. A coleta de dados se baseou em: pesquisa bibliográfica; pesquisa documental; e entrevista semiestruturada. Por fim, a análise e interpretação dos dados foi realizada com o auxílio do Software NVivo por meio da técnica de análise de conteúdo. Deste modo, a averiguação do diagnóstico organizacional proporcionou a organização uma apreciação crítica dos procedimentos utilizados pela gestão naquele determinado momento, além de descrever as variáveis que influenciam o negócio. É uma forma proativa de prevenção de problemas, correção de processos e implementação ou emprego de oportunidades. A interrelação existente entre as áreas funcionais é intangível e intrínseca a rotina organizacional, sendo que seu conhecimento e compreensão são vitais para o sucesso de uma organização.

Palavras-chave: Diagnóstico Organizacional; Agroindústria Familiar; Marketing; Produção; Gestão de Pessoas.

\section{The organizational diagnosis in family agroindustries: a study in a rural family agroindustry}

\begin{abstract}
This study aimed to diagnose and analyze the organizational dynamics that are established in the interface of the functional areas of organizational planning, marketing, production and operations, people management and finance under the impact of social variables and individual-group-organizational system, in addition to describing the interfaces, potentialities and fragilities that are established. In this context, the organizational diagnosis of the Sete Sabores Agroindustry, a rural family agroindustry located in the interior of the city of ljuí (RS), was carried out in a completer and more in-depth context. bakery and confectionery. Data collection was based on: bibliographic research; documentary research; and semi-structured interview. Finally, the analysis and interpretation of the data was performed using the NVivo Software through the technique of content analysis. Thus, the verification of the organizational diagnosis provided the organization with a critical appraisal of the procedures used by management at that particular moment, as well as describing the variables that influence the business. It is a proactive way of preventing problems, correcting processes and implementing or employing opportunities. The interrelation between the functional areas is intangible and intrinsic to the organizational routine, and their knowledge and understanding are vital to the success of an organization.
\end{abstract}

Keywords: Organizational Diagnosis; Family Agroindustry; Marketing; Production; People management.

Topic: Planejamento, Estratégia e Competitividade

Reviewed anonymously in the process of blind peer

Felipe Cavalheiro Zaluski

Universidade Regional do Noroeste do Estado do Rio Grande do Sul, Brasil http://lattes.cnpq.br/5563360256401044

http://orcid.org/0000-0003-0942-9180

felipezaluski@hotmail.com

Patrique Rosa Hedlund

Universidade Regional do Noroeste do Estado do Rio Grande do Sul, Brasil http://lattes.cnpq.br/2486724365095333

pa.tri.que@hotmail.com

\section{Jorge Oneide Sausen}

Universidade Regional do Noroeste do Estado do Rio Grande do Sul, Brasil http://lattes.cnpq.br/5913833180837421

josausen@unijui.edu.br
Received: 20/05/2018

Approved: 23/07/2018 Tarcisio Dorn de Oliveira
Universidade Regional do Noroeste do Estado do Rio Grande do Sul, Brasil
http://lattes.cnpq.br/1493478586678556 tarcisio.oliveira@unijui.edu.br
Referencing this:

ZALUSKI, F. C.; HEDLUND, P. R.; SAUSEN, J. O.; OLIVEIRA, T. D.. O diagnóstico organizacional em agroindústrias familiares: um estudo em uma agroindústria familiar rural. Revista Brasileira de Administração Científica, v.9, n.2, p.62-75, 2018. DOI: http://doi.org/10.6008/CBPC2179-684X.2018.002.0006

DOI: 10.6008/CBPC2179-684X.2018.002.0006 


\section{INTRODUÇÃO}

Uma análise das agroindústrias familiares rurais evidencia, de uma maneira geral, a existência de trajetórias únicas de evolução, diferente da percorrida pela grande agroindústria convencional (MIOR, 2007). Nesse contexto, a gestão das agroindústrias familiares rurais tem se apresentado, apesar de complexa, essencial para a competitividade atualmente, para isso, deve ser controlado cada processo e custo da propriedade, buscando informações que auxiliem os gestores nas tomadas de decisões.

Vale destacar que, nas agroindústrias familiares rurais, prevalece o sistema agroalimentar por motivos culturais, comerciais e produtivos, visto que, com produções em pequenas escalas, há uma dificuldade competitiva direta o grande setor industrial. Deste modo, uma das atuais preocupações relacionadas a gestão das agroindústrias é forma de apurar, analisar, controlar e gerir os processos organizacionais, objetivando a participação competitiva no mercado (WERNECK, 2002).

Com o atual crescimento econômico e a competitividade cada vez mais acentuada entre as organizações do mesmo segmento, muitos agricultores familiares buscam alternativas para ampliação da renda familiar e, com o caráter empreendedor, encontram na verticalização da produção uma brecha para escaparem das dificuldades encontradas, principalmente financeiras e da forte competitividade do mercado (PEREZ et al., 2009).

Diante disso, o diagnóstico organizacional permite detectar e analisar com aprofundamento as dificuldades e falhas que impedem que os objetivos planejados sejam alcançados com efetividade. Para Lacombe et al. (2003), "diagnóstico empresarial consiste no exame da situação de uma empresa, consubstanciando-o em conclusões sobre os aspectos analisados e com sugestões do que se deve fazer". 0 diagnóstico pode resultar em ações visando eliminar as dificuldades presentes nas diversas áreas de uma organização, otimizando desta forma todos os processos de trabalho.

Conforme os resultados de um diagnóstico organizacional realizado, podem ser feitos ajustes ou alterações na estrutura das organizações com o objetivo de adaptá-la às melhores técnicas de gestão (NEWMAN et al., 1992). Ainda, o diagnóstico organizacional auxilia os gestores no processo decisório e minimiza riscos de falta de informações, pois permite compreender a organização por meio da elucidação das dimensões de planejamento organizacional, marketing, produção e operações, gestão de pessoas, finanças, etc.. A análise de cada uma dessas dimensões proporciona uma fonte de informações que demonstra o contexto atual que a organização está inserida.

Os resultados de um diagnóstico organizacional permitem aos gestores terem uma visão do ambiente da organização e tem a possibilidade de direcionar seus recursos para os projetos que realmente são necessários e que poderão acarretar melhorias, permite ainda, a tomada de ações preventivas, na correção dos pontos fracos e falhas na rotina administrativa e operacional.

Portanto, este estudo objetiva-se em diagnosticar e analisar a dinâmica organizacional que se estabelece na interface das áreas funcionais de planejamento organizacional, marketing, produção e operações, gestão de pessoas e de finanças sob o impacto das variáveis do meio social e das dimensões 
indivíduo-grupo-sistema organizacional, além de descrever as interfaces, potencialidades e fragilidades que se estabelecem. Nesse contexto, procurou-se apresentar, em um âmbito mais completo e aprofundado, o diagnóstico organizacional da Agroindústria Sete Sabores, uma agroindústria familiar rural localizada no interior da cidade de ljuí (RS), que atua no ramo de produção de produtos na linha de panificados e confeitaria.

\section{REVISÃO TEÓRICA}

\section{Agroindústrias Familiares}

O setor da agroindústria familiar é composto por pequenos produtores, tanto rurais, como urbanos, de produtos com origem vegetal e animal (podendo ser orgânico ou não) além de produtos de panificação e massas. Esses produtores enquadram-se como micro e pequenos empresários que oferecem produtos ligados a cultura local e com baixa sofisticação tecnológica. O desenvolvimento desses produtos é elaborado de forma artesanal em pequenas instalações. Aonde por mais que sejam produções de processos simples, com baixo teor tecnológico, apresentam um grande potencial de agregação de valores (RUIZ et al., 2015).

Diante disso, Carvalheiro (2010) elucida que a agroindústria familiar pode ser compreendida como uma unidade de processo, de beneficiamento e de mutação de gêneros alimentícios localizada no meio rural ou nos aglomerados achegados, sendo geralmente uma propriedade de agricultor familiar, constituído por uma família ou uma associação de moradores de determinada localidade. Considerada um modelo alternativo de processo e/ou mutação da matéria-prima pelos agricultores, este cenário beneficia a superação do processo onde os agricultores produzem e entregam seus produtos in natura para terceiros realizarem o processamento e agregarem valor, possibilitando, assim, a admissão do produtor na cadeia produtiva.

Em outro dimensionamento, Hahn et al. (2017) expõe que determinadas agroindústrias mantem-se na clandestinidade ocasionada pelas dificuldades relacionadas à sua adaptação, aonde os inúmeros processos para aprovação do produto para o mercado, na visão do agricultor, gera um grande desgaste devido a esta operação sempre apresentar algo a ser modificado ou melhorado, o que prejudica em termos de recursos, riscos e tempo para o agricultor familiar adaptar-se.

Outra instabilidade encontrada é a carência de gestão para empreendimentos rurais, problema originado, pelo baixo nível de estudo dos agricultores, bem como, a omissão dos gestores das políticas e instituições visando prepará-lo para operar ou gerenciar o empreendimento. Hahn et al. (2017) ainda afirma que esses agricultores são confrontados com inúmeros obstáculos, desde financiamentos buscando a aquisição de maquinários para o empreendimento, matéria-prima, fluxo de caixa, custos, impostos e perdem-se com a parte burocrática. Ou seja, nenhum apoio governamental será satisfatório se não estiver adequado a realidade da agricultura familiar de forma a buscar o sucesso destes empreendimentos rurais.

Perante a Lei Federal no 11.326 de 24 de julho de 2006, o empreendedor familiar é aquele que desenvolve atividades no meio rural em área de até quatro módulos fiscais, e utiliza nas atividades e gestão do estabelecimento mão-de-obra predominantemente da família (BRASIL, 2006). Entretanto, diante de uma 
pequena escala de produção surge a inflexibilidade da legislação, aliando a qualidade a estrutura física, o legislativo qualifica essa produção como informal e para regularização seria necessário um grande investimento, pois no desenvolvimento de produtos alimentícios visando as pequenas unidades de processamento a qualidade do produto está coligada a qualidade da matéria prima, higiene dos trabalhadores que manipulam esse alimento, fluxograma da agroindústria, etc. (SILVEIRA et al., 2005).

As agroindústrias familiares tornam-se fundamentais devido ao seu importante papel no desenvolvimento das áreas rurais e da consolidação da agricultura familiar. Frente aos empecilhos encontrados pelos agricultores, as unidades de processamento de pequeno porte representam uma alternativa de renda e trabalho, possibilitando assim, a inclusão socioeconômica. Devido a este reconhecimento econômico e atender as necessidades do consumidor, a formalização destes estabelecimentos adquiriu uma grande importância, neste sentido, as agroindústrias familiares precisam desenvolver seus empregados de forma consciente, adotando boas práticas de fabricação e estar atentas legislações incidentes sobre a manipulação dos seus produtos (HAHN et al., 2017).

\section{Diagnóstico organizacional}

O diagnóstico organizacional objetiva-se em elucidar o mais fielmente possível a atual situação da organização e, a partir disso, apresentar possíveis soluções ou inconsistências que auxiliem a organização a potencializar seu desempenho. O conceito de diagnóstico organizacional define a necessidade de verificarse o desempenho da organização, de forma qualitativa, buscando encontrar os possíveis problemas e crises por ela vivenciados (PADULA et al., 1996).

Newman et al. (1980) define o diagnóstico organizacional como um processo de verificação temporal e espacial que busca representar a organização como um todo, demonstrando os possíveis desvios de desempenho, analisar as condições dos processos de determinados setores, ou seja, diagnosticar procedimentos que não estão claramente corretos e que poderiam estar mais alinhados com as necessidades e objetivos da organização.

Neste contexto, Lacombe et al. (2003) define o diagnóstico organizacional como um "[...] exame da situação de uma empresa, consubstanciando-o em conclusões sobre os aspectos analisados e com sugestões do que se deve fazer". Desse modo, o processo do diagnóstico organizacional permite detectar e analisar com mais detalhamento as dificuldades e falhas que impedem que os objetivos planejados pelos gestores sejam alcançados com efetividade.

O principal objetivo do diagnóstico organizacional consiste em conhecer e analisar o funcionamento da organização por completo, possibilitando uma avaliação de todos os seus aspectos, sejam estruturais, econômicos ou organizacionais (SANTOS et al., 2009). Segundo Berti (2001), esta avaliação permite verificar se a organização está sendo bem administrada ou não, para isso é necessário que a avaliação seja criteriosa e coerente com a realidade dos departamentos e áreas organizacionais. Portanto, o diagnóstico organizacional pode ser considerado uma primeira etapa de um processo de aprimoramentos que buscam 
proporcionar à organização condições necessárias para o desenvolvimento de seus objetivos e níveis desejados de eficiência e eficácia dos processos organizacionais.

A análise interna da organização por meio do diagnóstico organizacional, segundo Bateman et al. (1998), "[...] fornece aos tomadores de decisão estratégica um panorama das habilidades e recursos da organização, bem como de seus níveis de desempenho gerais e funcionais", diante disso, este processo consiste na verificação das qualidades e deficiências, ou seja, a evidenciação dos pontos fracos e pontos fortes, considerando também as possibilidades de mudança e adequação de processos de cada departamento.

Oliveira (2006) divide o diagnóstico organizacional em quatro fases. A primeira fase busca identificar uma hipótese ou problema que afeta a organização. A segunda fase busca reunir informações que caracterizem o problema. Já a terceira fase é a fase em que analisa as informações elucidadas, triangula diferentes informações para melhor identificação e definição do problema. E, por fim, a quarta e última fase consiste em confrontar as informações extraídas do diagnóstico e compará-los com as experiências anteriores, buscando propor e caracterizar possíveis meios de adequação dos problemas encontrados.

Assim, a partir dos resultados de um diagnóstico organizacional é possível compreender melhor toda a organização, por meio da elucidação das dimensões do planejamento organizacional, marketing, produção e operações, gestão de pessoas e finanças. Santos et al. (2009) ressalta também, que além da análise do ambiente interno, deve-se levar em conta o impacto das variáveis do meio social e das dimensões indivíduogrupo-sistema organizacional, além de descrever as interfaces, potencialidades e fragilidades que se estabelecem. Deste modo, o diagnóstico organizacional, quando utilizado como uma ferramenta estratégica, pode ser considerado não só como uma maneira de avaliação organizacional, mas também como parte do planejamento estratégico.

\section{METODOLOGIA}

O estudo utilizou-se de uma abordagem qualitativa, pois esta abordagem busca analisar e interpretar aspectos mais profundos, descrevendo a complexidade do comportamento humano, fornecendo uma análise mais detalhada sobre as investigações, hábitos, atitudes e tendências de comportamento (MARCONI et al., 2004).

Os procedimentos técnicos da pesquisa se classificam em pesquisa bibliográfica, desenvolvida a partir de material já elaborado, constituído principalmente de livros e artigos científicos da mesma temática. Ainda, classifica-se quanto aos objetivos como pesquisa descritiva, pois ela objetiva-se em descrever características de uma determinada população, fenômeno ou relações entre variáveis (TEIXEIRA et al., 2009), neste estudo esta abordagem buscou maior familiaridade com o problema das dinâmicas organizacionais que envolvem as áreas funcionais buscando torná-lo mais explícito e classifica-se como estudo de caso único, Yin (2001), define o estudo de caso como uma pesquisa empírica que averígua um fenômeno contemporâneo dentro do contexto da vida real, principalmente quando os limites entre o fenômeno e o contexto não são visivelmente evidentes. 
A coleta de dados foi realizada através da pesquisa de dados primários e secundários. A coleta de dados primários foi realizada por meio de entrevistas semiestruturadas, que para Triviños (1987), a entrevista semiestruturada é aquela que parte de certos questionamentos básicos, apoiados em teorias que interessam à pesquisa, e que, em seguida, oferecem amplo campo de interrogativas, frutos de novas sínteses que vão surgindo à medida que se recebem as respostas do entrevistado. Como coleta de dados secundários, utilizouse a pesquisa documental e bibliográfica, procurando obter informações nos relatórios administrativos, redes sociais da agroindústria, documentos de decisões estratégicas, relatórios internos, indicadores gerenciais e memorandos internos que colaborassem com a análise das informações elucidadas nas entrevistas.

A coleta de dados baseou-se em: pesquisa bibliográfica que foi executada para ter a base conceitual completa para sustentar a análise; pesquisa documental nos documentos internos disponibilizados pela agroindústria; entrevista semiestruturada realizada com os proprietários da agroindústria, visando conhecer os processos de cada departamento e analisar os pontos fortes e fracos que se estabelecem, as entrevistas tiveram a duração de aproximadamente uma hora e meia e foram gravadas, com o consentimento dos entrevistados, visando facilitar a posterior análise das informações elucidadas; e pesquisa de campo que ocorreu na própria agroindústria, afim de familiarizar com o ambiente e coletar informações não elucidadas nas demais coletas de dados. Por fim, a análise e interpretação dos dados foi realizada com o auxílio do Software NVivo por meio da técnica de análise de conteúdo (BARDIN, 2011).

\section{RESULTADOS E DISCUSSÃO}

A Agroindústria Sete Sabores iniciou suas atividades em setembro do ano de 2011, foi constituída através do Programa Estadual de Agroindústria Familiar (PEAF) e possuí sua sede no interior da cidade de ljuí, no Estado do Rio Grande do Sul. Seu ramo de produção é baseado em produtos na linha de panificados e confeitaria.

O diagnóstico organizacional realizado na Agroindústria Sete Sabores utilizou-se do conceito abordado por Oliveira (2006), onde o diagnóstico segue quatro etapas para o seu desenvolvimento, conforme apresentado no referencial teórico. Deste modo, a primeira fase identificou que a organização apresenta problemas no nível de divisão de tarefas e organização dos processos entre os setores de marketing, produção e operações, gestão de pessoas, finanças e, ainda, englobando o planejamento organizacional. A segunda fase compreendeu em identificar os processos de cada departamento. A terceira fase buscou-se analisar as informações encontradas nas coletas de dados e confrontá-las com os principais estudos e abordagens teóricas. A quarta parte buscou-se descrever as interfaces, potencialidades e fragilidades que se estabelecem em cada departamento, conforme apresentado a seguir.

\section{Planejamento Organizacional}

Na visão de Oliveira (2006), o planejamento envolve um modo de pensar, sobre os questionamentos: o que fazer, como, quando, quanto, para quem, por que, por quem e onde, portanto, a finalidade de se fazer um planejamento é estar orientando a organização para a tomada de decisões. No entanto estas decisões 
são voltadas para o presente, porém se antevendo de situações adversas previstas no futuro, e assim, analisando se a estrutura da organização suportaria esses resultados negativos.

A Agroindústria Sete Sabores não possuí um planejamento formalizado de seus objetivos, contudo, se preza muito a contínua sobrevivência da organização e subsistência financeira da família proprietária. Outro fator considerado é o controle, ou seja, as receitas e as despesas onde se poderia observar os possíveis investimentos e o que será mais viável produzir entre outros aspectos que qualificarão o processo decisório gerando mais eficiência e melhores resultados não é formalizado, ficando os proprietários sem informações suficientes que o auxiliem a tomada de decisões.

No entendimento de Lampert et al. (2010), o planejamento, do ponto de vista empresarial, é um processo que estabelece objetivo, define linhas de ação e planos detalhados para atingi-los, determinando os recursos necessários à consecução dos mencionados objetivos. Existem fatos relevantes no planejamento da referida organização na parte de compra de produtos, principais elementos são: preço, nível de estoque, compras anteriores, entre outros.

Para a criação da Agroindústria foram realizadas consultorias pela Empresa de Assistência Técnica e Extensão Rural do Estado do Rio Grande do Sul (EMATER/RS), onde auxiliaram na projeção de custos, informações nutricionais dos produtos, qualificação profissional dos proprietários e atualmente auxiliam na elaboração dos projetos de produção da merenda escolar.

\section{Marketing}

Segundo Cobra (2015) o marketing está relacionado às ações de mercado que precisam ser trabalhados de forma eficiente para garantir boas relações com o público consumidor e se materializa na relação satisfatória entre a empresa e o cliente. A Agroindústria Sete Sabores não possuí um plano de marketing devidamente estruturado, nem planejamento de ações ou estratégias formais para o marketing, contudo, utiliza-se de redes sociais para apresentar seus produtos aos consumidores finais, bem como manter um relacionamento com os mesmos, outra forma de promover seus produtos é pela conversa informal efetuada com os consumidores e comerciários no momento da venda, bem como participação em feiras e eventos regionais.

Para Kotler (2012) um produto é algo que pode ser oferecido a um mercado, para sua apreciação, aquisição, uso ou consumo, que pode satisfazer um desejo ou uma necessidade. Em todos os produtos da organização é incluído na embalagem o selo Sabor Gaúcho, conforme Decreto Estadual no 49341 de 05 de julho de 2012, o selo é anexado na etiqueta do produto que destaca os produtos oriundos da agricultura familiar e garantir desta forma sua procedência (RIO GRANDE DO SUL, 2012a).

Kotler (2012) identifica que a segmentação de mercado está no ápice da estratégia de marketing. Segundo ele, a segmentação de mercado, a ideia mais importante para orientar a estratégia, começa não com a distinção de possibilidades de produto, mas sim com a distinção de interesses ou de necessidades de clientes. Conforme Cobra (2015) exemplifica a segmentação de mercado, no caso em estudo, a mesma pode ser definida como: Geográfica, pois é voltada aos consumidores da Região Noroeste do Estado do Rio Grande 
do Sul, mais especificamente no município de sua sede e arredores; e como: Comportamental, visto que é voltada aos consumidores que optam por produtos mais elaborados, de produção manual, com matériaprima menos industrializada e com maior qualidade.

O mix de marketing é formado por um conjunto de variáveis controláveis que influenciam a forma como os consumidores respondem ao mercado. Com base nisso, estruturar um bom composto de marketing é uma estratégia de vantagens competitiva para a organização e a questões importantes com relação ao mix, ambiente de negócios e do mercado é extremamente dinâmico (KOTLER et al., 2005).

Na perspectiva de Kotler (2012), o produto inclui não só bens e serviços, mas também marcas, embalagens, serviço aos clientes, o produto nem sempre é físico pode ser serviços pessoais, locais, organizações, ideias, o produto deve obrigatoriamente ser aquele desejado pelo cliente estar dentro das suas expectativas e satisfazer suas necessidades. Seus principais produtos são: bolachas, cucas, pães, salgadinhos assados e fritos, tortas, doces diversos, pizzas, lasanhas, bolos doces e salgados, etc.. A organização preza pela produção de produtos com qualidade e a utilização de matéria-prima de boa procedência e qualidade, a produção segue um manual de boas práticas de fabricação. Além disso, a Agroindústria Sete Sabores efetua a entrega dos produtos no comércio, escolas ou onde o cliente solicitar, sem cobrança direta deste serviço.

A partir desta base todo dinheiro cobrado por um produto ou prestação de serviço é denominado de preço, de forma mais abrangente, preço é soma monetária que os consumidores trocam por receber um benefício, ou determinado produto, ou serviço (KOTLER, 2012). Desta forma a realização da formação de preço na organização é baseada principalmente pelo preço de compra das matérias-primas, somado as despesas administrativas e uma margem de lucro que a organização quer obter com a venda. $\mathrm{O}$ preço praticado pela organização é, em algumas vezes, maior que o praticado pela concorrência, neste sentido o valor agregado do produto é o diferencial encontrado para manter suas vendas constantes.

Kotler (2012) explica que a praça ou os canais de distribuição são "um conjunto de organizações interdependentes envolvidas no processo de tornar-se um produto ou serviço disponível para o consumidor final ou organizacional". Pode-se definir como praça os locais de venda dos produtos no município de ljuí e nas feiras realizadas nas cidades vizinhas, bem como na distribuição dos produtos na merenda escolar.

Promoção são os métodos utilizados para refletir uma melhor proposta do produto ou serviço para os consumidores. Realçando a publicidade e propaganda que é feito do mesmo, deve mostrar os porquês de as pessoas necessitarem de tal produto ou serviço, e a satisfação que obterão de fazer o uso do mesmo. As decisões estratégicas também devem ser tomadas com relação a cada método individual de promoção. (KOTLER, 2012). Em nível de promoção, verifica-se que a organização se utiliza de redes sociais para a apresentação de seus produtos aos consumidores, visto o crescimento das relações virtuais de compra e procura de informações de produtos.

\section{Produção e Operações}

O principal objetivo das operações, "[...] é garantir que os processos de produção e entrega de valor ao cliente sejam alinhados com a intenção estratégica da empresa" (CORRÊA, 2009). A principal demanda de 
produção da agroindústria é a oriunda da venda de produtos para a merenda escolar dos municípios de ljuí e Coronel Barros, que gera cerca de sessenta por centro do faturamento da mesma, em virtude de ser amparada pela Lei 11.947 de 16 de junho de 2009, art. 14, que dispõem, “[...] no mínimo 30\% (trinta por cento) deverão ser utilizados na aquisição de gêneros alimentícios diretamente da agricultura familiar e do empreendedor familiar rural" (BRASIL, 2009).

Outro objetivo da produção é manter abastecido, com os produtos, os pontos de venda dos municípios citados acima, a agroindústria possui uma ordem de produção semanal, e como resultado mensal ocorre a produção de aproximadamente setecentos quilos de produtos. 0 mercado priorizado é o da merenda escolar, visto que a demanda é regida por contratos o que garante a produção por cerca de seis meses. Quanto ao abastecimento dos pontos de venda, os produtos como pães, cucas e bolos são fabricados todas as segundas, quartas e sextas-feiras, em razão dos seus prazos de validade, já os produtos como bolachas e salgadinhos são fabricados e entregues conforme ocorre suas saídas nos mercados e pontos de venda.

O modelo de transformação encontrado na agroindústria segue uma linha bem estruturada da entrada da matéria-prima até a saída do produto já finalizado. O sistema de produção de manufatura, encontrado na agroindústria, se caracteriza pelo processo de Jobbing, "[...] alta variedade em tipos de produto e baixos volumes de produção" (LOPES, 2010), ainda, são fabricados na agroindústria mais de cinquenta produtos diferentes.

A produção por este sistema possibilita um produto praticamente exclusivo para o cliente, o que justifica a produção manual, que pode, dependendo da solicitação do cliente, ser diferenciado e específico. O processo de produção utilizado é o Arranjo Físico Celular, pois os recursos transformados se movimentam em uma parte específica aonde recursos transformadores se encontram, segundo Corrêa (2009), argumenta que quando o grupo de colaboradores ao realizar a gestão e operar elementos das células buscam trabalhar mais o sentido de 'propriedade'.

A empresa utiliza somente um programa de computador, que serve para ajustar a etiqueta utilizada pela agroindústria na balança etiquetadora, nela é visualizado o nome da empresa, o número de cadastro no Programa Estadual da Agroindústria Familiar e o Selo Sabor Gaúcho. O selo Sabor Gaúcho, conforme Decreto Estadual no 49341 de 05 de julho de 2012, é um selo anexado na etiqueta do produto que, destaca os produtos oriundos da agricultura familiar (RIO GRANDE DO SUL, 2012a).

Quanto a estrutura da agroindústria, de acordo com Silva (2008), "os Layouts são os arranjos físicos dos equipamentos e dispositivos no local de trabalho e de como vai ser o fluxo do trabalho", com isso, podese observar que o espaço físico possui um layout bem organizado, onde minimiza-se a movimentação feita pelos colaboradores na realização das tarefas.

No que se refere à ergonomia, Corrêa (2009), revela que maquinários, equipamentos, dispositivos e ou uma simples ferramenta manual deverá ser desenvolvido considerando as medidas do corpo humano. 0 primeiro processo ergonômico acontece na organização dos equipamentos e matéria-prima, pois a agroindústria possuí mesas e bancadas mais baixas do que as normalmente encontradas no comércio, o que 
auxilia no processo de produção devido à altura dos colaboradores, outro fato encontrado é a disposição de uma das máquinas do processo, que é posicionada de forma mais baixa em relação as demais, visando facilitar o manuseio das massas e reduzir o esforço realizado.

O planejamento e controle da produção acontece da seguinte forma, para a venda nos pontos específicos ocorre um levantamento da demanda e da média de venda no período, que se caracteriza como demanda a curto prazo e a demanda identificada a médio prazo se trata dos contratos da merenda escolar que são feitos a cada seis meses. Não ocorre um planejamento adequado da compra de matéria-prima, já que sua compra é realizada a partir do momento que se tem a demanda de produção, o único planejamento de compra que ocorre é relacionado aos fornecedores de matéria-prima.

\section{Gestão de Pessoas}

A gestão de pessoas pode ser definida como a uma função que permite a colaboração das pessoas, empregados, funcionários, recursos humanos, ou qualquer denominação utilizada, para alcançar os objetivos organizacionais e individuais (CHIAVENATO, 2010). A organização é uma agroindústria de produção familiar onde predomina a interação entre relações familiares e trabalho, os proprietários e seus filhos dirigem o processo produtivo, correlacionando com as demais tarefas pertinentes a propriedade rural e atividades familiares.

Por se tratar de uma organização caracterizada como agroindústria familiar rural, a mesma não pode possuir colaboradores formais, visto que vai contra a Lei Especifica 13.921 de 17 de janeiro de 2012, que caracteriza as agroindústrias, portanto não há um plano de gestão de pessoas em virtude de não haver funcionários na organização, contudo há uma disposição na referida Lei que libera a contratação formal de um funcionário na agroindústria pelo período de cento e vinte dias no ano, entretanto, essa contratação nunca foi utilizada pela agroindústria (RIO GRANDE DO SUL, 2012b).

A comunicação entre os familiares é estabelecida informalmente, e em âmbito de liderança, o mesmo fica a cargo do proprietário, que procura incentivar o bom desempenho pessoal, o crescimento e o desenvolvimento da Agroindústria Sete sabores. O proprietário busca a integração da família para alcançar os mesmos objetivos, essa função administrativa aciona e dinamiza a propriedade, onde todos os integrantes da família têm direito de opinar e dar sugestões para melhorar os processos produtivos e aproveitar melhor o tempo e reduzir o desperdício de operações desnecessárias. A motivação acontece através da valorização de cada membro da família, onde se busca melhoria de vida que motiva os envolvidos. No qual os investimentos em tecnologias realizados na agroindústria são em busca de um trabalho com menos esforço, mais praticidade e agilidade.

O desenho organizacional envolve a definição da estrutura básica da empresa e como tarefa empresarial é dividida e atribuída entre departamentos, a agroindústria possui uma estrutura organizacional bastante simples, devido ao fato de ser uma agroindústria familiar de pequeno porte, onde cada integrante da família pode realizar diversas atividades dentro da organização, não havendo cargos ou descrição de 
tarefas formalizado, as informações acerca disso são repassadas verbalmente aos executantes, contudo, há algumas atividades que são de responsabilidade de determinadas pessoas dentro da agroindústria.

o organograma é relativamente simples, sendo que a maioria das atividades constadas no organograma é exercida pelos proprietários com auxílio da sua família, como exemplificado anteriormente, não há como definir formalmente cada atividade para cada membro da unidade familiar, visto que o conceito de agroindústria é realmente o auxílio mútuo e correlativo entre a família. As áreas da propriedade são compostas basicamente por: administrativo, que efetuaria os processos referentes a administração, controles de faturamento, compras etc., que estaria disposto todo o processo produtivo e vendas, onde se encontraria os processos de venda e negociações dos contratos de venda dos produtos. Todos os familiares possuem conhecimento das atividades diárias, e conseguem manter andamento dos processos na ausência de algum integrante da família.

O processo de desenvolver pessoas, trabalha as práticas de treinamento e desenvolvimento, neste sentido, houve uma preocupação dos proprietários para com seus filhos, os mesmos cursam o ensino superior em áreas afins com a agroindústria, curso de graduação em Administração e em Agronomia, os conhecimentos adquiridos pelos membros da família são de certa forma utilizados para o aprimoramento dos processos da agroindústria, trazendo especialização e conhecimentos para a família.

A cultura familiar visualizada na organização tem vantagens, isto significa que seu jeito é diferente porque é expressa na forma como seus integrantes se comportam, mostrando mais lealdade, porque vivem em um ambiente familiar, a interação e a união afetiva estão intimamente presentes no dia a dia, inclusive influenciando o comportamento e decisões da empresa, criando um clima de união dentro da agroindústria. Com todo esse cenário a agroindústria se fortalece, tornando-se mais veloz, dinâmica e competitiva

\section{Finanças}

Atualmente, as organizações, de uma forma geral, estão inseridas em um mercado a cada dia mais competitivo e com rápido progresso na tecnologia de processos e produtos. Esta nova realidade faz com que os gestores enfrentem diversos desafios relacionados à tomada de decisões que direcionem ao alcance da missão empresarial, tanto mais, quando se trata de ações que estão diretamente ligadas a situação econômico-financeira da organização.

Silva (2010) define a análise financeira e dos indicadores como uma das ferramentas mais importantes que a contabilidade gerencial pode oferecer, haja vista a grande quantidade de informações que estas proporcionam. Portanto, por meio da análise econômica financeira é possível extrair informações sobre a posição passada, presente e futura da empresa. A agroindústria Sete Sabores não possuí balanços patrimoniais ou demonstrações contábeis formalizadas e descritas, por ser uma agroindústria familiar rural mantém seus registros de gastos e informações financeiras de maneira informal.

Mesmo sem demonstrações contábeis formalizadas e padronizadas, a agroindústria utiliza-se de um caderno de controle de pedidos para anotação das informações das vendas efetuadas aos pontos de venda, neste caderno de controle de pedidos é anotado todas as informações das vendas, percentual de comissão 
disponibilizado ao ponto de venda, ou feiras em que a agroindústria participa, e na próxima entrega é efetuado o controle da quantidade de produtos que não foram vendidos e retornaram a agroindústria, efetuando-se assim um desconto dos valores anotados primeiramente no caderno de controle. Para as vendas realizadas as escolas que a compra de produtos para a merenda escolar, o controle é realizado diretamente no bloco de Nota Fiscal do Produtor (NFP).

A agroindústria em estudo não possuí nenhum controle sobre seus investimentos, custos, pagamentos e despesas diretas da organização, visto que o capital financeiro é o mesmo da família proprietária, não havendo distinção ou separação formalizada da mesma, neste sentido não há como elucidar qual seria o valor atual em caixa, ou disponível, da agroindústria. O faturamento médio mensal da organização é de aproximadamente $\mathrm{R} \$ 10.000,00$; contudo, há vendas de produtos que o retorno não é financeiro, em dinheiro, e sim pela troca de produtos, um exemplo é a venda de produtos para determinado posto de combustível, onde o ganho da agroindústria se dá pela troca de produtos por combustível, neste sentido, nem toda venda resulta em valores financeiros em espécie, e sim em troca de bens.

A agroindústria possuí alguns financiamentos de pagamento anual, existem outros pagamentos mensais, como boletos de água, luz, cartão de crédito utilizado para compras de produtos em supermercados. Atualmente a agroindústria está conseguindo manter seus pagamentos e financiamentos em dia, visto que mesmo informalmente há uma gestão do capital financeiro pelo proprietário, onde ele analisa os meses em que há maior venda e destina parte do montante recebido para pagamento das contas que vencerão futuramente, provisionando os valores para pagamento futuro.

\section{CONCLUSÕES}

O estudo realizado na Agroindústria Sete Sabores resultou um diagnóstico da agroindústria em estudo, permitindo a posterior tomada de ações preventivas, na correção dos pontos fracos e falhas na rotina administrativa e o aproveitamento das oportunidades e pontos positivos, conforme os resultados e sugestões descritos.

Devido ao grande zelo pela continuidade da Agroindústria Sete Sabores e a estabilidade financeira fornecida pela empresa a família proprietária, é sugerido que seja desenvolvido um planejamento formal dos objetivos almejados e da forma de gestão adotada para então começar a mensurar indicadores de processos que balizaram o desenvolvimento do trabalho aliado aos objetivos dos gestores para a agroindústria. Aconselha-se que, a gestão da área administrativa e das atividades operacionais sejam reestruturados, visando reduzir a sobrecarga de tarefas do proprietário, para que ele possa ocupar mais sua carga horaria com atividades pertinentes a gestão da agroindústria.

No diagnóstico organizacional foi evidenciado que a Agroindústria Sete Sabores não apresenta um plano de marketing estruturado, entretanto, a utilização de redes sociais para promover seus produtos é uma ótima estratégia para destacar a empresa no mercado, propõem-se que a mesma procure uma maior visibilidade nas referidas redes sociais buscando potencializa-las com imagens dos produtos e informações sobre eles. Outra indicação seria a utilização de uma pesquisa de satisfação aplicada a rede de escolas que 
adquirem os produtos com a agroindústria para merenda escolar, buscando fidelizar os clientes, otimizar seu atendimento e potencializar seus produtos.

Em relação a dimensão Preço, do mix de marketing, recomenda se a adaptar seus preços conforme um sistema de custos e gastos correlacionados ao processamento do produto, evidenciou-se que o preço é superior em relação a concorrência, entretanto uma análise mais apurada sobre os preço e gastos de produção auxiliaria a definir o preço praticado e nortear se é viável ou não produzir específicos produtos. Evidencia-se que a singularidade da Agroindústria Sete Sabores é a qualidade de seus produtos entregues, tendo em vista que no mercado em que abrange a agroindústria já se tornou referência, bem como, suas vendas estão cobrindo as demandas de merendas escolares para os municípios de ljuí e Coronel Barros.

Entretanto, foi identificado que a empresa não apresenta um programa de planejamento e controle interno estruturado para a produção, em razão da produção ser desenvolvida informalmente e sem ferramenta para instrumentalizar sua gestão, neste contexto, conforme esclarecido no estudo, os gestores possuem uma vasta experiência na área, conseguindo assim, manter um controle sobre seus resultados. Contudo, aconselha-se a desenvolver um mapeamento de todas as ações advindas do processo produtivo, especialmente no intuito de controlar custos, entradas e saídas dos produtos na agroindústria.

Em relação a dimensão financeira, foi analisado que a agroindústria Sete Sabores não apresenta balanço patrimonial ou as demais demonstrações contábeis formalizadas e descritas publicamente, devido a agroindústria ser uma empresa familiar e rural a mesma possui seus registros de custos e dados financeiros de maneira informal, então, aconselha-se que seja realizado uma avaliação dos processos do departamento financeiro e contábil da agroindústria tendo em vista regularizar e obter dados claros acerca da situação financeira da organização.

A cultura familiar visualizada na Agroindústria Sete Sabores tem vantagens, isto significa que seu jeito é diferente porque é expressa na forma como seus integrantes se comportam, mostrando mais lealdade, porque vivem em um ambiente familiar, a interação, e essa união afetiva está intimamente presente no dia a dia, inclusive influenciando o comportamento e decisões da organização, criando um clima de união dentro da mesma. Com todo esse cenário a agroindústria se fortalece, tornando-se mais veloz, dinâmica e competitiva.

Deste modo, a averiguação do diagnóstico organizacional proporcionou a organização uma apreciação crítica dos procedimentos utilizados pela gestão naquele determinado momento, além de descrever as variáveis que influenciam o negócio. É uma forma proativa de prevenção de problemas, correção de processos e implementação ou emprego de oportunidades. A inter-relação existente entre as áreas funcionais é intangível e intrínseca a rotina organizacional, sendo que seu conhecimento e compreensão são vitais para o sucesso de uma organização.

\section{REFERÊNCIAS}

BARDIN, L.. Análise de conteúdo. São Paulo: Edições 70. 2011.
BATEMAN, T. S.; SNELL, S. A.. Administração: construindo vantagem competitiva. São Paulo: Atlas, 1998. 
BERTI, A.. Diagnóstico empresarial: teoria e prática. São Paulo: Ícone, 2001

BRASIL. Lei $\mathbf{1 1 . 3 2 6}$ de 24 de julho de 2006. Estabelece as diretrizes para a formulação da Política Nacional da Agricultura Familiar e Empreendimentos Familiares Rurais. Brasília: DOU, 2006.

BRASIL. Lei n.11947 de 16 de junho de 2009. Institui sobre o atendimento da alimentação escolar. Brasília: DOU, 2009.

CARVALHEIRO, E. M.. A construção social de mercados para os produtos da agroindústria familiar. Tese (Doutorado em Desenvolvimento Rural) - Universidade Federal do Rio Grande do Sul, Porto Alegre, 2010.

CHIAVENATO, I.. Gestão de pessoas: o novo papel dos recursos humanos nas organizações. 3 ed. Rio de Janeiro: Elsevier, 2010.

COBRA, M.. Administração de marketing no Brasil. 4. ed. Rio de Janeiro: Elsevier, 2015.

CORRÊA, H. L.; CORRÊA, C. A.. Administração de Produção e de Operações: manufatura e serviços: uma abordagem estratégica. São Paulo: Atlas, 2009.

HAHN, C. L.; CASARIN, V. A.; SANTOS, A. V.; MIRANDA, R. L.; ORTIZ, L. C. V.. Análise de mercado dos produtos da agroindústria familiar: estudo de caso do perfil do consumidor e do produtor Santo-Angelense, Rio Grande do Sul, Brasil. Revista Espacios, v.38, n.5, 2017.

KOTLER, P.. Administração de marketing. 14 ed. São Paulo: Pearson Education do Brasil, 2012.

KOTLER, P.; ARMSTRONG, G.. Princípios de marketing. 9 ed. São Paulo: Prentice Hall, 2005.

LACOMBE, F. J. M.; HEILBORN G. L. J.. Administração: princípios e tendências. São Paulo: Saraiva, 2003.

LAMPERT, A. L.; BAGGIO, A. F.. Planejamento

Organizacional. Ijuí: EdUnijui, 2010.

LOPES, A. O.; SIEDENBERG, D.; PASQUALINI, F.. Gestão da Produção. ljuí: EdUnijuí, 2010.

MARCONI, M. A; LAKATOS, E. V.. Metodologia científica. São Paulo: Atlas, 2004.

MIOR, L. C.. Agricultura familiar, agroindústria e desenvolvimento territorial. In: COLÓQUIO INTERNACIONAL DE DESENVOLVIMENTO RURAL SUSTENTÁVEL. Anais. Florianópolis: UFSC, 2007.

NEWMAN, W. H.; WARREN, K.. Administração Avançada. São Paulo: Atlas, 1992
OLIVEIRA, D. P. R. Planejamento Estratégico: conceitos, metodologias e práticas. 22 ed. São Paulo: Atlas, 2006

PADULA, A. D.; VADON, J.. Uma metodologia de Diagnóstico Organizacional Global para a consultoria de gestão de pequenas e médias empresas. Revista de Administração, v.31, n.1, p.32-43, 1996

PERES, P. C.; RAMOS, V. G.; WIZNIEWSKY, C. R. F.. A produção de derivados da cana-de-açúcar como alternativa para a agricultura familiar: estudo de caso na agroindústria familiar rural Lazzaretti e Picolotto - Constantina/RS. In: ENCONTRO NACIONAL DE GEOGRAFIA AGRÁRIA, 19. Anais. São Paulo: USP, 2009.

RIO GRANDE DO SUL. Decreto $\mathbf{n} .49341$ de 5 de julho de 2012. Cria o Programa de Agroindústria Familiar do Estado do Rio Grande do Sul, institui o selo de marca de certificação 'Sabor Gaúcho' e dá outras providências. Porto Alegre: DOE, 2012a.

RIO GRANDE DO SUL. Lei n.13921 de 17 de janeiro de 2012. Institui a Política Estadual de Agroindústria Familiar. Porto Alegre: DOE, 2012b.

RUIZ, M. R.; VENTURINI, V.; CAMBERLIN, W.; UCHOA JUNIOR, P. P. M.. Agroindústria familiar de Londrina-PR. Revista de Ciências Jurídicas, v.3, n.2, 2015

SANTOS, L. H. Z.; CANÊO, L. C. Contribuições do Diagnóstico Organizacional para o planejamento de intervenções em Psicologia Organizacional em uma empresa do ramo metalúrgico. In: CONGRESSO DE INICIAÇÃO CIENTÍFICA, 21. Anais. Bauru: Unesp, 2009.

SILVA, J. P.. Análise financeira das empresas. 10 ed. São Paulo: Atlas, 2010.

SILVEIRA, P. R. C.; HEINZ, C.. Controle de qualidade normativo e qualidade ampla: princípios para reestruturação e qualificação da produção artesanal de alimentos. In: CONGRESSO INTERNACIONAL DE DESENVOLVIMENTO RURAL E AGROINDÚSTRIA FAMILIAR. Anais. Santa Maria: UFSM, 2005.

TEIXEIRA, E. B.; ZAMBERLAN, L.; RASIA, P. C.. Pesquisa em Administração. ljuí: EdUnijuí, 2009.

TRIVIÑOS, A. N. S.. Introdução à Pesquisa em Ciências Sociais: a Pesquisa Qualitativa em Educação: O Positivismo, A Fenomenologia, O Marxismo. São Paulo: Atlas, 2009.

WERNECK, E. S. O.. Uma Proposta de Sistema de Custos para uma Empresa Agroindustrial de Aves de Corte. Dissertação (Mestrado em Engenharia de Produção) Universidade Federal de Santa Catarina, Florianópolis, 2002.

YIN, R. K.. Estudo de caso: planejamento e métodos. Porto Alegre: Bookman, 2001.

A CBPC - Companhia Brasileira de Produção Científica (CNPJ: 11.221.422/0001-03) detém os direitos materiais desta publicação. Os direitos referem-se à publicação do trabalho em qualquer parte do mundo, incluindo os direitos às renovações, expansões e disseminações da contribuição, bem como outros direitos subsidiários. Todos os trabalhos publicados eletronicamente poderão posteriormente ser publicados em coletâneas impressas sob coordenação da Sustenere Publishing, da Companhia Brasileira de Produção Científica e seus parceiros autorizados. Os (as) autores (as) preservam os direitos autorais, mas não têm permissão para a publicação da contribuição em outro meio, impresso ou digital, em português ou em tradução. 